\title{
Analysis of Screening Results of 1012 Sperm Donors in China: A Retrospective Cohort Study of Geographic Differences in Semen Quality
}

\section{Qian-Cheng Zhao}

Peking University Third Hospital

\section{Zhe Zhang}

Peking University Third Hospital

Lian-Ming Zhao

Peking University Third Hospital

Zhen-Feng Deng

Peking University Third Hospital

Jiang-Man Gao

Peking University Third Hospital

Hong-Liang Zhang

Peking University Third Hospital

\section{Hao-Cheng Lin}

Peking University Third Hospital

\section{De-Feng Liu}

Peking University Third Hospital

Jia-Ming Mao

Peking University Third Hospital

Hai-Tao Zhang

Peking University Third Hospital

\section{Yu-Long Chen}

Peking University Third Hospital

\section{Wen-Hao Tang}

Peking University Third Hospital

Hui Jiang ( $\sim$ jianghui55@163.com )

Peking University Third Hospital

\section{Research Article}

Keywords: geographic differences, semen quality, sperm donor, sperm concentration

Posted Date: October 18th, 2021

DOI: https://doi.org/10.21203/rs.3.rs-959968/v1

License: @ (i) This work is licensed under a Creative Commons Attribution 4.0 International License. Read Full License 


\section{Abstract}

Male reproductive health has become a concern in public health, and semen quality is essential to male reproduction. To investigate the geographical differences in semen quality of sperm donors from the north and south of China, a total of 1012 sperm donors from all over China were enrolled in this work, which were divided by their residential latitude. There were statistically significant differences in sperm concentration among men from different latitudes in China $(P=0.04)$. The sperm concentrations of people from $18^{\circ}-27^{\circ}$ north latitude were lower than those from $36^{\circ}-45^{\circ}$, and $45^{\circ}-54^{\circ}$ (median $131,134,146$, respectively, $P=0.021\left[18^{\circ}-27^{\circ}\right.$ vs. $\left.36^{\circ}-45^{\circ}\right]$ and $P=0.01\left[18^{\circ}-27^{\circ}\right.$ vs. $\left.\left.45^{\circ}-54^{\circ}\right]\right)$. It was further confirmed when the samples were re-divided into 2 groups (typically north and south) that contains 667 samples. The analysis also showed a significant difference in terms of the regions to which the samples belonged (the median of the north is 134; the median of the south is $125 ; \mathrm{P}=0.015)$. Although other sperm parameters don't show significant change with latitude, some of them possess a strong relationship with sperm concentration $(r=-0.19364, P<0.001)$. Specifically, we suppose that environmental pollution and mental stress due to increased population may be the main factors in the difference.

\section{Introduction}

Male reproductive health has become a great concern in public health, which is associated with the quality of the whole population ${ }^{[1]}$. In a recent study, the researchers found that the sperm quality of Estonian men were better than those from the Finnish in terms of total sperm number and normal sperm count ${ }^{[2]}$, but the limitation of this study was that samples came from four countries located around the Baltic sea. Moreover, relatively concentrated geographical distribution was not enough to explain whether the results were related to geographical differences, and the results may be due to the different conditions of recruiting volunteers, semen analysis, and data processing methods ${ }^{[3]}$. However, the studies in semen quality among provinces and municipalities in Spain showed that, even in a particular country with uniform processing methods, there were still geographic differences in semen quality ${ }^{[4]}$. This finding supported the hypothesis that there were regional differences in semen quality. Similarly, a study from Qatar also indicated that even within the specific recruitment agency, the differences in semen quality between the two regions still existed ${ }^{[5]}$. Our team, noticed that these results were specifically applied to Europe, but little has been done to investigate variations in Asia settings. Although prior preliminary comparisons about the (abnormal rate of semen parameters) conducted by reproductive centers across China suggested a difference of the north and the south, to be more specific, the abnormal rate of most areas in the south was higher than the north, which may be related to regional pollution ${ }^{[6-8]}$. However, the differences might be sampling procedures rather than the geographical area per $\mathrm{se}^{[9]}$, there was still a lack of overall investigation on the geographic differences of semen quality in China. Therefore, this study will mainly focus on the differences of male semen quality in the north and south of China by comparisons of different latitudes and different regional divisions.

\section{Materials And Methods}

\section{Recruitment}

Based on the standard protocol for human sperm banking revised by the Ministry of Health of the People's Republic of China, we selected eligible sperm donors from 27 provinces and cities in China from a large sperm bank in Beijing from October 2015 to May 2019, sperm donors must be between 22 and 44 years of age. And they should meet the sperm bank's requirements, such as no noticeable baldness or hair loss, no color weakness, no color blindness. All the sperm donors must be in good health, on the basis of the results of both physical examination and psychologic evaluation, including a reproductive system examination. In particular, our donors were not allowed to smoke or drink in advance, and as a matter of fact, during the experiment time, they never or seldom break the rules. We conducted rigorous medical screening for these sperm donors, and those with family history of hereditary diseases were excluded. Potential donors 
must pass laboratory tests to exclude sexually transmitted infections and genetic diseases of high-risk individuals, including human immunodeficiency virus 1 and 2, hepatitis B and C, syphilis, gonorrhea, mycoplasma, chlamydia, cytomegalovirus, Toxoplasma gondii, rubella virus, herpes simplex virus types 1 and 2, and karyotype analysis. Because the polymorphism of human chromosome has certain clinical effects which features the abortion, the stillbirth and the infertility, we chose this phenotype normal male with chromosome karyotype $46, X Y$ in the screening process. The donors' semen quality was analyzed by using standardized methods outlined in the World Health Organization Laboratory Manual by trained technicians. Our screening criteria for donors' semen quality were based on the basic human sperm bank standards and technical specifications for donors' semen quality. During the screening criteria, internal quality control was carried out to ensure that there was no significant difference between the research results of different technicians. The donors' semen quality should meet all of the following criteria: (1) all the semen samples should be fresh and drained into a sterile container by masturbating. (2) The liquefaction time of semen samples should less than 60 minutes, and the sperm concentration should be $\left.\geq\left(60 \times 10^{6}\right) \mathrm{ml}^{-1}\right)$, the semen volume should be $\geq 2 \mathrm{ml}$, the normal sperm morphology percent should be $>9 \%$, the forward motile sperm percentage should be $₫ 60 \%$,the total motile sperm count should be $\geq 12 \times 10^{6}$ ), the frozen-thaw survival rate should be $\geq 60 \%$. (3) The abstinence period of each sperm donor volunteer is 3 days.

\section{Data Collection}

Trained sperm bank doctors used structured questionnaires to collect demographic and lifestyle information. The survey covers date of birth, ethnicity, education level, marriage status, childbearing history, profession, native place, Year of semen examination and abstinence period. Each sperm donor was graded on a physical examination, including height and weight. According to World Health Organization(WHO) guidelines, body mass index (BMI) is calculated as weight (kg) divided by height squared $\left(\mathrm{m}^{2}\right)^{[10]}$.

\section{Semen collection and semen analysis}

All the semen samples were discharged into a specific sperm cup of the sperm bank through masturbating in a private room. Then the semen samples were immediately delivered to the sperm bank laboratory through a delivery window in the semen collection room. The aseptic operation should be guaranteed throughout the process, and semen samples were analyzed by trained clinical technicians in the same laboratory. The liquefied semen samples were analyzed under $37^{\circ} \mathrm{C}$ water bath within an hour after collection. Sperm analysis was performed using a computer-aided sperm analysis (CASA, SuiJia Software, Beijing, China) to determine sperm concentration and progressive motility within $1 \mathrm{~h}$. According to the guidelines of the World Health Organization fifth edition ${ }^{[11]}$. The semen quality parameters that were assessed included appearance, semen volume, viscosity, agglutination, liquefaction time, pH value, sperm concentration, sperm motility, and percentage of motile sperm. According to the scheme formulated by the World Health Organization ${ }^{[12]}$, the volume was determined by drawing up the entire sample into a wide-mouthed $(\sim 2 \mathrm{~mm}) 5 \mathrm{~mL}$ disposable calibrated serological pipette (nonpyrogenic) by means of a mechanical device. To assess sperm concentration and motility, $10 \mu l$ of mixed semen was placed in a clean Makler room (at $37^{\circ} \mathrm{C}$ ) for assess and was covered lightly with the cover glass ${ }^{[13]}$, then was examined at a total magnification of $\times 200$, ten of the 100 squares in the microscope field were randomly scanned, and the sperm count was recorded by cytometer. The $\mathrm{pH}$ value was determined by $\mathrm{pH}$ test paper, then compared with calibration tape to determine the $\mathrm{pH}$ value. With the help of an ocular grid, we calculated that progressive motility and non-progressive motility, then add them up to figure out the total motility. In the end, we figure out the total sperm number as semen volume multiplied by sperm concentration and figure out the total motile sperm count as total sperm number multiplied

by total motility ${ }^{[14]}$. We analyzed each semen sample twice. In the course of the study, internal quality control was carried out to ensure that there were no significant deviations from the results of the clinical technicians. 


\section{Statistical analysis}

We applied median and interquartile range (IQR) to describe continuous variables, and frequency and percentage for discrete variables. All statistical analyses were performed with SPSS 25.0 (SPSS, Chicago, IL, USA). Pearson correlation coefficient was used to evaluate the relationship between different sperm parameters. For differences between regions or latitudes, we chose Mann-Whitney $U$ testto examine the statistical significance ${ }^{[15]}$. For non-normal distribution, median and interquartile range (IQR) and the Kruskal-Wallis $\mathrm{H}$ test were used as appropriate ${ }^{[16]}$. The extensive experimental data set,obtained from this stability study $\llbracket$ was used to build multiple linear regression models, so that correlated the confounders that affected semen parameters. All the analyses went through a two-sided test and, if $\mathrm{P}<0.05$ denotes statistical significance.

\section{Results}

A total of 1,012 participants from 2015 to 2019 were enrolled in the study. The spatial distribution of these 1,012 participants from 27 provinces in China is shown in Fig. 1, the provinces with more than 100 participants were Beijing Municipality (177), Hebei (146) and Shandong (104) provinces. Generally speaking, the "Qinling Mountain-Huaihe River" line is an essential geological boundary to divide the north and south regions in China. The characteristics $(N=1012)$ of the research objects in the north and south regions of China divided by the "Qinling Mountain-Huaihe River " line are shown in Table 1. The mean(IQR) age of all participants was 26 (23-31) years old. Among the 1012 participants, 752 were from northern China, and the median (IQR) age was 27 (23-31) years old; 260 were from southern China, and the median (IQR) age was 24 (22-29) years old. About $94 \%$ of the subjects were from Han ethnic group. As shown in Table 2, progressive motility was significantly negatively associated with volunteer status, and positively associated with BMI. Semen volume was significantly positively associated with marital status. On either side of Qinling Mountain-Huaihe River line that divides the north and south of China, the statistical results showed no significant difference in semen quality between the two regions (Table $3, \mathrm{P}>0.05$ ). Although most of the parameters do not differ among the regions, some of them shows strong correlation with each other. Table 4 showed their mutual Pearson orrelation coefficient. Semen volume exhibits a weak but convincing negative correlation to sperm concentration $(r=-0.194, P<0.001)$, which is clearly demonstrated in Fig. 2a. Moreover, frozen-thawed sperm concentration is strongly correlated to sperm concentration (Fig. 2b). In order to further illustration the regional difference in semen quality, we refined the north and south by excluding remote areas while setting provinces in South-eastern China (including Jiangsu, Shanghai, Zhejiang, Fujian, Jiangxi, Anhui) and Southern China(including Guangdong, Guangxi, Hainan, Hongkong, Macao, Taiwan) as the South, provinces in Northern China (including Beijing, Tianjin, Hebei, Shanxi, Inner Mongolia), and Northeast (including Heilongjiang, Jilin, Liaoning) China as the North, and the number of statistical samples was reduced to 667 , then the result showed a significant difference in sperm concentration between the two regions (Table 5, $\mathrm{P}=0.015$ ), and the people in the north have significantly higher sperm concentration (Fig. 3a). We did not observe any significant differences for semen volume, progressive motility, post-thaw survival rate, frozen-thawed sperm concentration, and frozen-thawed progressive motility across different regions $(P>0.05)$. To further verify this result, we further divided China into four regions by latitude, including regions between 18-27 degrees north latitude, 27-36 degrees north latitude, 36-45 degrees north latitude, 45-54 degrees north latitude, and carried out the analysis. As shown in Table 6, there were statistically significant differences in sperm concentration among men from different latitudes in China $(P=0.04)$, but no statistically significant differences in semen volume, progressive motility, frozen-thawed sperm concentration, frozen-thawed progressive motility and post-thaw survival rate. The sperm concentrations of people from $18^{\circ}-27^{\circ}$ north latitude were lower than those from $36^{\circ}-45^{\circ}$, and $45^{\circ}-54^{\circ}$ (median $131,134,146$, respectively, $P=0.021\left[18^{\circ}-27^{\circ}\right.$ vs. $\left.36^{\circ}-45^{\circ}\right]$ and $\mathrm{P}=0.01\left[18^{\circ}-27^{\circ}\right.$ vs. $\left.\left.45^{\circ}-54^{\circ}\right]\right)$. Although there is no significant statistical difference in semen volume among these people $(P=0.084)$, as shown in (Fig. $3 b)$, we could observe that the semen volume gradually decreases with the increases of latitude. 


\section{Discussion}

Over the years, there has been many debates about whether there are differences in semen quality between different regions. After the quantitative analysis of the correlation of semen quality in 667 sperm donors between the north and south of China, our data revealed that donors living in the north of China have significantly higher sperm concentration than those in the south of China (the median were $134,125, P=0.015)$. Similarly, there were statistically significant differences in sperm concentration among men from different latitudes in China ( $P=0.04)$. Sperm concentration is an important parameter for semen, indicating level of male's fertility. Our results are the first to comprehensively describe differences in semen quality between the north and south of China, and regional differences in semen quality may have biological significance.

A representative study with a large number of healthy men from China showed that age-related changes were not found in sperm concentration among different age groups of Chinese men ${ }^{[17]}$, consistent with a previous meta-analysis by a stronger methodology which found no relationship between male age and sperm concentration ${ }^{[18]}$. The same results showed that there were no significant differences between male age and sperm concentration in our research $(P>0.05)$.

According to relevant statistics, the distribution of Chinese population has undergone tremendous changes. In recent years, the population of the north has been on a decline, while the south shows an opposite trend ${ }^{[19]}$, which was believed to be related to the migration caused by different distribution of regional economy ${ }^{[20]}$. As a result, larger population in the south contributes to its heavier level of pollution. Consistent with previous studies demonstrating the negative impact that pollution has on semen quality ${ }^{[21]}$, we observed a higher concentration of sperm in the semen sampled from donors living in the north, in accordance with the milder pollution in the north. In addition, people tend to suffer from greater psychological burden in more densely populated areas. The association between mental stress and reduced semen quality was supported by a study that built a biological plausibility ${ }^{[22]}$. Under mental stress, the endocrine system of men is interrupted, which manifests as low levels of testosterone and luteinizing hormone and subsequently interferes with sperm production, thus resulting in decreased male fertility ${ }^{[23]}$. Therefore, mental stress may also account for the regional differences in sperm concentration between the north and south of China. In summary, the influence of environmental factors and lifestyle on semen quality may be explained by the changes in fertility patterns brought about by migration ${ }^{[24]}$.

In addition to the factors mentioned above, some other factors such as seasons, ethnic, dietary pattern and obesity may also affect semen quality.

In an assessment of male infertility data in the United States, compared with Asian men, the white men have higher sperm production but lower sperm concentration ${ }^{[25]}$. Because of conditions, only $5.6 \%$ of our sperm donors are from ethnic minorities, and the most of sperm donors are from Han ethnic group, With limited data, we were unable to assess whether the difference in semen quality between north and south China was related to ethnic.

In terms of diet, a cross-sectional study in Spain that assessed the relationship between dietary patterns and fertility had suggested that adherence to a healthy diet positively correlates with sperm concentration and sperm motility ${ }^{[26]}$. Different from the western diet pattern,the traditional Chinese diet is based on grains, and, due to the difference in latitude and climate, the southern people eat rice and the northern people eat flour. At present, there is no literature on the effect of rice and flour on semen quality. However, some tables made from reliable blood glucose index (GI) data sources found that sperm concentration was negatively correlated with the frequency and quantity of grain consumption ${ }^{\text {[27] }}$, Because grains are rich in starch with high starch content. When dietary intake leads to an increase in blood sugar, hyperglycemia will increase the risk of inflammation, which will lead to a decline in male semen quality ${ }^{[28]}$. In summary, data on the relationship between diet and semen quality or male infertility factors are still limited. Additional prospective studies, 
including those exploring biological mechanisms, are needed to explain the relationship between dietary patterns and male fertility ${ }^{[29]}$. Therefore, how the difference in diet structure between the south and the north influences semen quality still needs further exploration.

in the matter of seasons, as was reported, the parameters such as sperm concentration and total sperm count collected by outdoor workers in summer were significantly lower than that from the same workers collected in winter ${ }^{[30]}$. While in another study, the effect of seasonal changes on semen quality could not be discovered. Some analysts speculate that the high temperatures may affect testicular spermatogenesis. However, the study conducted by Golher et al suggested that the sperm function parameters of crossbred bucks, which were reared in subtropical climate, did not show any difference in different seasons, which may be related to the advanced testicular temperature regulation mechanism in the body ${ }^{[31]}$. Our study did not record the seasons when volunteer donated their semen due to limited statistical conditions, but we will incorporate this factor into statistics in future studies.

As for obesity, reduced fertility in obese men is thought to be linked to changes in the levels of hormones that form sperm ${ }^{[32]}$. Since the obese sperm donors were excluded from the current study, our results are thus independent of the influence of obesity. It is worth mentioning that compared with the sperm donors in the south, the average BMI of the sperm donors in the north is significantly higher $(P=0.002)$. We also noted that previous studies had indicated differences in the distribution of BMI between adolescents in the north and the south of China. Adolescents in the north of China generally have a bulky figure, a phenomenon that is independent of the level of socio-economic development ${ }^{[33]}$. Some studies believe that the adaptation of the human body to the surrounding environment may cause regional differences of human growth and development ${ }^{[34]}$. Moreover, sufficient sunshine, low annual average temperature and observable seasonal temperature variability in the north of China are all beneficial to body fat accumulation of individuals ${ }^{[35]}$, which may be the reason for higher BMI of sperm donors in the north of china.

Although the reason for the geographical variation of semen quality is not yet clear, lifestyle and environmental factors are supposed to be the causes ${ }^{[36]}$. Specifically, we suppose that environmental pollution and mental stress due to increased population may be the main factors in the difference.

\section{Limitations}

This study is only a preliminary study on the regional differences in semen quality of sperm donors between the north and south of china. Future investigations are still needed to further validate the geographic variations in larger regions with a more accurate study design to address the issues listed above.

\section{Conclusions}

We concluded that the North-South differences in China donors mainly affect sperm concentration, which should be considered in similar analyses. Since the majority of the participants were from Northern China, the results regarding southern China should be interpreted with caution. More participants of southern should be included in the future analysis to exam the conclusion and validate the generalizability.

\section{Abbreviations}

\section{WHO}

World Health Organization

BMI

body mass index 
IQR

interquartile range

\section{Declarations}

\section{Acknowledgements}

The authors thank all participants for their contributions to this study. Special thanks to Dr. Chi Zhang for his assistance in statistical analysis.

\section{Authors' Contributions}

Qiancheng Zhao, Zhe Zhang and Lianming Zhao drafted the manuscript; Qiancheng Zhao, Lianming Zhao and Hongliang Zhang were responsible for collecting and collating the data of donors; Qiancheng Zhao and Zhenfeng Deng participated in the creation of figures and tables; Jiangman Gao and Lianming Zhao participated in the semen analysis ; Qiancheng Zhao, Haitao Zhang, Defeng Liu, Haocheng Lin, Zhe Zhang and Jiaming Mao participated in the proofreading of this paper $\otimes$ Yulong Chen provided advice on the geographical division of China. Hui Jiang and Wenhao Tang provided the overall principle and direction of the study.

\section{Funding}

This study was supported by Beijing Natural Science Foundation (Grant No. 7182177 and No. 7194333), National Natural Science Foundation of China (Grant No. 81871204 and No.81901535).

\section{Availability of data and materials}

The datasets used and analysed during the current study are available from the corresponding author on reasonable request.

\section{Ethics approval and consent to participate}

This study has been approved by the Ethics Committee of Peking University Third Hospital (2020SZ-002). This study was performed in accordance with the Declaration of Helsinki, all methods were performed in accordance with the relevant guidelines and regulations. The requirement for informed consent was waived by the committee, because the data used in this study were collected from previously routine clinical procedures and were anonymous to all research investigators.

\section{Consent for publication}

Not applicable.

\section{Competing Interests}

The authors declare that they have no competing interests.

\section{Author details}

1.Department of Human sperm bank, Peking University Third Ho spital, Beijing 100191, China

2.Department of Urology, Peking University Third Hospital, Beijing 100191, China

3.Department of Natural Medicine, Peking University School of Pharmaceutical Sciences, Beijing 100191, China 
4.Department of Obstetrics and Gynecology, Peking University Third Hospital, Beijing 100191, China

5.Department of Urban and Rural Planning, Peking University, Beijing 100871, China

Ethical approval

This study has been approved by the Ethics Committee of Peking University Third Hospital (2020SZ-002). The requirement for informed consent was waived by the committee, because the data used in this study were collected from previously routine clinical procedures and were anonymous to all research investigators.

\section{References}

1. Tomaiuolo R, Veneruso I, Cariati F, D'Argenio V: Microbiota and Human Reproduction: The Case of Male Infertility. High-throughput 2020, 9(2).

2. $\mathrm{N} \mathrm{J}, \mathrm{E} \mathrm{C}, \mathrm{I}$ N, M P, J S, AG A, AM A, TB H, A H, TK J et al: East-West gradient in semen quality in the Nordic-Baltic area: a study of men from the general population in Denmark, Norway, Estonia and Finland. Human reproduction (Oxford, England) 2002, 17(8):2199-2208.

3. Auger J, Jouannet P: Evidence for regional differences of semen quality among fertile French men. Fédération Francaise des Centres d'Etude et de Conservation des Oeufs et du Sperme humains. Human reproduction (Oxford, England) 1997, 12(4):740-745.

4. Lopez-Teijon M, Elbaile M, Alvarez JG: Geographical differences in semen quality in a population of young healthy volunteers from the different regions of Spain. Andrologia 2008, 40(5):318-328.

5. Elbardisi H, Majzoub A, Al Said S, Al Rumaihi K, El Ansari W, Alattar A, Arafa M: Geographical differences in semen characteristics of 13892 infertile men. 2018(2090-598X (Print)).

6. Yan L, Xiaoyang Y, Xiongbo G, Danli C: Analysis of semen detection results of $\mathbf{5 6 4 8}$ infertile male cases in Guangzhou China (in Chinese). Chinese Journal of Health Laboratory Technology 2014, 2014,24(08):1125-1127.

7. Baoliang M, Ke G, Si C, Kangning C: Semen quality analysis of 6325 infertile men in Gansu China(in Chinese). Chinese Journal of Andrology 2019, 33(01):36-39.

8. Yuxia W, Wencheng C, Jie L, Guijiang W: Analysis of semen quality of 1626 infertile men in western Guangxi China(in Chinese). Chinese Journal of Human Sexuality 2017, 26(11):116-118.

9. Fisch H, Goluboff ET: Geographic variations in sperm counts: a potential cause of bias in studies of semen quality. Fertility and sterility 1996, 65(5):1044-1046.

10. Obesity: preventing and managing the global epidemic. Report of a WHO consultation. World Health Organization technical report series 2000, 894:i-xii, 1-253.

11. Cooper TG, Noonan E, von Eckardstein S, Auger J, Baker HW, Behre HM, Haugen TB, Kruger T, Wang C, Mbizvo MT et al: World Health Organization reference values for human semen characteristics. Hum Reprod Update 2010, 16(3):231-245.

12. WHO, 1992 World Health Organization (WHO). WHO Laboratory Manual for the Examination of Human Semen and Sperm-Cervical Mucus Interactio. 3rd ed. Cambridge, United Kingdom: Cambridge University Press; 1992.

13. Makler A: The improved ten-micrometer chamber for rapid sperm count and motility evaluation. Fertil Steril 1980, 33(3):337-338.

14. World Health Organization. (2010) WHO Manual for the Examination and Processing of Human Semen, 5th edn. World Health Organization, Geneva.

15. Bürkner PC, Doebler P, Holling H: Optimal design of the Wilcoxon-Mann-Whitney-test. Biometrical journal Biometrische Zeitschrift 2017, 59(1):25-40. 
16. Chan Y, Walmsley RP: Learning and understanding the Kruskal-Wallis one-way analysis-of-variance-by-ranks test for differences among three or more independent groups. Phys Ther 1997, 77(12):1755-1762.

17. Zhu QX, Meads C, Lu ML, Wu JQ, Zhou WJ, Gao ES: Turning point of age for semen quality: a population-based study in Chinese men. Fertil Steril 2011, 96(3):572-576.

18. Kidd SA, Eskenazi B, Wyrobek AJ: Effects of male age on semen quality and fertility: a review of the literature. Fertil Steril 2001, 75(2):237-248.

19. Qian D: Population Mobility and Urban Future (in Chinese). THINK TANK 2017, (01):34-39.

20. Danhua L, Xiaoyi L, Xiaoming L, Xiuyun L: A Comparison of Social Adaptation among Rural-to-Urban Migrants with Different Careers [in Chinese]. Chinese Mental Health Journal 2007, 21(6) 400-403.

21. Zhang HT, Zhang Z, Cao J, Tang WH, Zhang HL, Hong K, Lin HC, Wu H, Chen Q, Jiang H: Ambient ozone pollution is associated with decreased semen quality: longitudinal analysis of 8945 semen samples from 2015 to 2018 and during pollution-control period in Beijing, China. Asian journal of andrology 2019, 21(5):501-507.

22. Ilacqua A, Izzo G, Emerenziani GP, Baldari C, Aversa A: Lifestyle and fertility: the influence of stress and quality of life on male fertility. Reproductive biology and endocrinology : RB\&E 2018, 16(1):115.

23. King JA, Rosal MC, Ma Y, Reed GW: Association of stress, hostility and plasma testosterone levels. Neuro endocrinology letters 2005, 26(4):355-360.

24. Zou Z, Hu H, Song M, Shen Y, Guo X, McElreavey K, Bittles AH, Wang W: Semen quality analysis of military personnel from six geographical areas of the People's Republic of China. Fertility and sterility 2011, 95(6):2018-2023, 2023.e2011-2013.

25. Khandwala YS, Zhang CA, Li S, Behr B, Guo D, Eisenberg ML: Racial Variation in Semen Quality at Fertility Evaluation. Urology 2017, 106:96-102.

26. Salas-Huetos A, James ER, Aston KI, Jenkins TG, Carrell DT: Diet and sperm quality: Nutrients, foods and dietary patterns. Reproductive biology 2019, 19(3):219-224.

27. Atkinson FS, Foster-Powell K, Brand-Miller JC: International tables of glycemic index and glycemic load values: 2008. Diabetes care 2008, 31(12):2281-2283.

28. Kristo AS, Matthan NR, Lichtenstein AH: Effect of diets differing in glycemic index and glycemic load on cardiovascular risk factors: review of randomized controlled-feeding trials. Nutrients 2013, 5(4):1071-1080.

29. Liu CY, Chou YC, Chao JC, Hsu CY, Cha TL, Tsao CW: The Association between Dietary Patterns and Semen Quality in a General Asian Population of 7282 Males. PLoS One 2015, 10(7):e0134224.

30. Levine RJ, Mathew RM, Chenault CB, Brown MH, Hurtt ME, Bentley KS, Mohr KL, Working PK: Differences in the quality of semen in outdoor workers during summer and winter. N Engl J Med 1990, 323(1):12-16.

31. Golher DM, Kumaresan AA-O, Saraf KK, Chhillar S, Nayak S, Tripathi UK, Bhaskar CN, Lathwal SS, Mohanty TK: Influence of season and climatic variables on testicular cytology, semen quality and melatonin concentrations in crossbred bucks reared under subtropical climate. 2018(1432-1254 (Electronic)).

32. Škurla M, Rybář R: Obesity and reduced fertility of men. Ceska gynekologie 2018, 83(3):212-217.

33. Cheng-ye J, Jun-ling S: Geographic and population difference of BMI in Chinese school-age youth (in Chinese).

Chinese Journal of Pediatrics 2004, 42(5):328-332.

34. Takahashi E: Geographic distribution of human stature and environment J Anthrop Soc Nippon 1971, 39(3): $259-285$.

35. Ji Chengye, Yuan Jie, Daying W: Environmental Factors Contributing to Regional Differences in the Growth of China's Rural Youth (in Chinese). Sports Science 1992, (05):42-46+94-95.

36. Sharpe RM: Lifestyle and environmental contribution to male infertility. British medical bulletin 2000, 56(3):630-642. 
Table 1

Characteristics of the study subjects by sperm donors in the north and south of china.

\begin{tabular}{|c|c|c|c|c|}
\hline Characteristic & All subjects & North of China & South of China & $P$ \\
\hline & $\mathrm{N}=1012(\%)$ & $\mathrm{N}=752(\%)$ & $\mathrm{N}=260(\%)$ & \\
\hline Age, years & & & & $<0.001$ \\
\hline $22-24$ & $126(12.5)$ & $85(11.3)$ & $41(15.8)$ & \\
\hline $25-29$ & $403(39.8)$ & $270(35.9)$ & $133(51.2)$ & \\
\hline $30-39$ & $417(41.2)$ & $345(45.9)$ & $72(27.7)$ & \\
\hline $40-44$ & $66(6.5)$ & $52(6.9)$ & $14(5.3)$ & \\
\hline Median (IQR) & $26(23-31)$ & $27(23-31)$ & $24(22-29)$ & \\
\hline Ethnicity & & & & 0.038 \\
\hline Han & $955(94.4)$ & $703(93.5)$ & $252(96.9)$ & \\
\hline Others & $57(5.6)$ & $49(6.5)$ & $8(3.1)$ & \\
\hline Education & & & & $<0.001$ \\
\hline Junior college and lower & $167(16.5)$ & $114(15.2)$ & $25(9.6)$ & \\
\hline Undergraduate & $612(60.5)$ & $456(60.6)$ & $156(60)$ & \\
\hline Postgraduate and higher & $233(23.0)$ & $182(24.2)$ & $79(30.4)$ & \\
\hline Marriage & & & & $<0.001$ \\
\hline Unmarried & $769(76.0)$ & $546(72.6)$ & $223(85.8)$ & \\
\hline Married & $243(24.0)$ & $206(27.4)$ & $37(14.2)$ & \\
\hline Volunteer status & & & & $<0.001$ \\
\hline students & $399(39.4)$ & $253(33.6)$ & $146(56.2)$ & \\
\hline others & $613(60.6)$ & $499(66.4)$ & $114(43.8)$ & \\
\hline BMI & & & & 0.009 \\
\hline underweight $(<18.5$ kg/m2) & $8(0.8)$ & $5(0.7)$ & $3(1.2)$ & \\
\hline normal weight (18.5-24.9kg/m2) & $812(80.2)$ & $588(78.2)$ & $224(86.2)$ & \\
\hline overweight (25-29.9 kg/m2) & $192(19.0)$ & $159(21.1)$ & $33(12.6)$ & \\
\hline
\end{tabular}


Table 2

Multiple linear regression were used to estimate $95 \mathrm{Cls}$ with adjustment for age, ethnicity, education, smoking and marital status.

\begin{tabular}{|c|c|c|c|c|c|c|}
\hline \multirow[t]{2}{*}{ Characteristic } & \multicolumn{6}{|c|}{ Semen Parameters } \\
\hline & $\begin{array}{l}\text { Semen } \\
\text { volume, ml }\end{array}$ & $\begin{array}{l}\text { Sperm } \\
\text { concentration, } \\
\left(10^{6}\right) / \mathrm{ml}\end{array}$ & $\begin{array}{l}\text { Progressive } \\
\text { motility, \% }\end{array}$ & $\begin{array}{l}\text { Frozen- } \\
\text { thawed sperm } \\
\text { concentration, } \\
\left(10^{6}\right) / \mathrm{ml}\end{array}$ & $\begin{array}{l}\text { Frozen- } \\
\text { thawed } \\
\text { Progressive } \\
\text { motility, \% }\end{array}$ & $\begin{array}{l}\text { Post-thaw } \\
\text { survival rate, } \\
\%\end{array}$ \\
\hline & $\beta(95 \% \mathrm{Cl})$ & $\beta(95 \% \mathrm{Cl})$ & $\beta(95 \% \mathrm{Cl})$ & $\beta(95 \% \mathrm{Cl})$ & $\beta(95 \% \mathrm{Cl})$ & $\beta(95 \% \mathrm{Cl})$ \\
\hline Age, years & $\begin{array}{l}-0.017(-0.227 \\
0.146)\end{array}$ & $\begin{array}{l}0.034(-4.778 \\
12.148)\end{array}$ & $\begin{array}{l}-0.022(-1.420 \\
0.791)\end{array}$ & $\begin{array}{l}0.064(-0.453 \\
4.681)\end{array}$ & $\begin{array}{l}-0.024(-2.719 \\
1.437)\end{array}$ & $\begin{array}{l}0.039(-0.007 \\
0.022)\end{array}$ \\
\hline Marriage & $\begin{array}{l}0.078(0.010 \\
0.460)^{b}\end{array}$ & $\begin{array}{l}-0.067(-19.290 \\
1.077)\end{array}$ & $\begin{array}{l}-0.053(-2.274 \\
0.386)\end{array}$ & $\begin{array}{l}-0.040(-4.722 \\
1.457)\end{array}$ & $\begin{array}{l}0.006(-2.299 \\
2.704)\end{array}$ & $\begin{array}{l}0.027(-0.011 \\
0.024)\end{array}$ \\
\hline $\begin{array}{l}\text { Volunteer } \\
\text { status }\end{array}$ & $\begin{array}{l}0.008(-0.179 \\
0.220)\end{array}$ & $\begin{array}{l}0.004(-8.632, \\
9.478)\end{array}$ & $\begin{array}{l}-0.106(-2.833 \\
-0.472)^{a}\end{array}$ & $\begin{array}{l}0.017(-2.135 \\
3.349)\end{array}$ & $\begin{array}{l}0.032(-1.294 \\
3.146)\end{array}$ & $\begin{array}{l}0.073(-0.001 \\
0.030)\end{array}$ \\
\hline BMI & $\begin{array}{l}0.013(-0.156, \\
0.239)\end{array}$ & $\begin{array}{l}-0.005(-9.726 \\
8.208)\end{array}$ & $\begin{array}{l}0.086(0.440 \\
2.778)^{a}\end{array}$ & $\begin{array}{l}0.001(-2.661 \\
2.769)\end{array}$ & $\begin{array}{l}0.021(-1.482 \\
2.915)\end{array}$ & $\begin{array}{l}-0.019(-0.020 \\
0.011)\end{array}$ \\
\hline Ethnicity & $\begin{array}{l}0.035(-0.150 \\
0.535)\end{array}$ & $\begin{array}{l}0.028(-8.467 \\
22.555)\end{array}$ & $\begin{array}{l}-0.018(-2.608 \\
1.445)\end{array}$ & $\begin{array}{l}0.021(-3.138 \\
6.276)\end{array}$ & $\begin{array}{l}-0.002(-3.918 \\
3.704)\end{array}$ & $\begin{array}{l}0.034(-0.012 \\
0.041)\end{array}$ \\
\hline Education & $\begin{array}{l}0.019(-0.097 \\
0.175)\end{array}$ & $\begin{array}{l}0.051(-1.466 \\
10.816)\end{array}$ & $\begin{array}{l}0.032(-0.419 \\
1.185)\end{array}$ & $\begin{array}{l}0.051(-0.442, \\
3.285)\end{array}$ & $\begin{array}{l}0.013(-1.206 \\
1.812)\end{array}$ & $\begin{array}{l}-0.012(-0.014, \\
0.007)\end{array}$ \\
\hline \multicolumn{7}{|c|}{ a $P$-value $<0.01$, analysis of variance. } \\
\hline \multicolumn{7}{|c|}{ b P-value $<0.05$, analysis of variance. } \\
\hline
\end{tabular}

Table 3

Distribution of semen quality parameters by sperm donors in the north and south of china. $(\mathrm{N}=1012)$

\begin{tabular}{|llll|}
\hline Characteristic & North of China & South of China & $P$ \\
\hline Semen volume, $\mathrm{ml}$ & $(\mathrm{N}=752)$ & $(\mathrm{N}=260)$ & \\
\hline Sperm concentration, $\left(10^{6}\right) / \mathrm{ml}$ & $3.0(2.4-4.0)$ & $3.2(2.4-4.4)$ & 0.142 \\
\hline Progressive motility, \% & $134.0(106.0-168.0)$ & $128.2(102.3-163.0)$ & 0.155 \\
\hline Frozen-thawed sperm concentration, $\left(10^{6}\right) / \mathrm{ml}$ & $71.9(63.0-84.9)$ & $70.0(62.0-82.0)$ & 0.379 \\
\hline Frozen-thawed progressive motility, \% & $53.0(48.0-58.0)$ & $52.0(48.0-58.0)$ & 0.223 \\
\hline Post-thaw survival rate, \% & $0.8(0.8-0.9)$ & $0.8(0.7-0.9)$ & 0.256 \\
\hline Data are shown as median $(\mathrm{IQR}) .{ }^{\prime}{ }^{\prime} \mathrm{N}^{\prime}$ refers to the number of subjects in each category. & $65.0(60.0-71.0)$ & 0.964 \\
\hline
\end{tabular}


Table 4

Pearson correlation efficient between semen parameter.

\begin{tabular}{|c|c|c|c|c|c|c|c|}
\hline & & $\begin{array}{l}\text { Semen } \\
\text { volume, } \\
\text { ml }\end{array}$ & $\begin{array}{l}\text { sperm } \\
\text { concentration, } \\
\left(10^{6}\right) / \mathrm{ml}\end{array}$ & $\begin{array}{l}\text { Progressive } \\
\text { motility, \% }\end{array}$ & $\begin{array}{l}\text { Frozen- } \\
\text { thawed sperm } \\
\text { concentration, } \\
\left(10^{6}\right) / \mathrm{ml}\end{array}$ & $\begin{array}{l}\text { Frozen- } \\
\text { thawed } \\
\text { progressive } \\
\text { motility, \% }\end{array}$ & $\begin{array}{l}\text { Post- } \\
\text { thaw } \\
\text { survival } \\
\text { rate, \% }\end{array}$ \\
\hline \multirow[t]{2}{*}{$\begin{array}{l}\text { Semen volume, } \\
\mathrm{ml}\end{array}$} & $\begin{array}{l}\text { Pearson } \\
\text { Corr. }\end{array}$ & 1 & $-0.194^{*}$ & $<0.001$ & $-0.175^{\star}$ & $-0.065^{\star}$ & $-0.074^{*}$ \\
\hline & $P$ & - & $<0.001$ & 0.985 & $<0.001$ & 0.040 & 0.019 \\
\hline \multirow{2}{*}{$\begin{array}{l}\text { Sperm } \\
\text { concentration, } \\
\left(10^{6}\right) / \mathrm{ml}\end{array}$} & $\begin{array}{l}\text { Pearson } \\
\text { Corr. }\end{array}$ & $-0.194^{*}$ & 1 & $0.081^{*}$ & 0.859* & 0.043 & -0.042 \\
\hline & $P$ & $<0.001$ & - & 0.010 & $<0.001$ & 0.171 & 0.189 \\
\hline \multirow[t]{2}{*}{$\begin{array}{l}\text { Progressive } \\
\text { motility, \% }\end{array}$} & $\begin{array}{l}\text { Pearson } \\
\text { Corr. }\end{array}$ & $<0.001$ & $0.081^{*}$ & 1 & $0.073^{*}$ & $0.547 *$ & $-0.378 *$ \\
\hline & $P$ & 0.985 & 0.010 & - & 0.020 & $<0.001$ & $<0.001$ \\
\hline \multirow{2}{*}{$\begin{array}{l}\text { Frozen-thawed } \\
\text { sperm } \\
\text { concentration, } \\
\left(10^{6}\right) / \mathrm{ml}\end{array}$} & $\begin{array}{l}\text { Pearson } \\
\text { Corr. }\end{array}$ & $-0.175^{\star}$ & $0.859 *$ & $0.073^{*}$ & 1 & $0.076^{*}$ & 0.007 \\
\hline & $P$ & $<0.001$ & $<0.001$ & 0.020 & - & 0.017 & 0.821 \\
\hline \multirow{2}{*}{$\begin{array}{l}\text { Frozen-thawed } \\
\text { progressive } \\
\text { motility, \% }\end{array}$} & $\begin{array}{l}\text { Pearson } \\
\text { Corr. }\end{array}$ & $-0.0647 *$ & 0.043 & $0.547 *$ & $0.076 *$ & 1 & $0.553^{\star}$ \\
\hline & $P$ & 0.040 & 0.171 & $<0.001$ & 0.017 & - & $<0.001$ \\
\hline \multirow[t]{2}{*}{$\begin{array}{l}\text { Post-thaw } \\
\text { survival rate, \% }\end{array}$} & $\begin{array}{l}\text { Pearson } \\
\text { Corr. }\end{array}$ & $-0.074^{\star}$ & -0.042 & $-0.378^{\star}$ & 0.007 & $0.553^{\star}$ & 1 \\
\hline & $\mathrm{P}$ & 0.019 & 0.189 & $<0.001$ & 0.821 & $<0.001$ & - \\
\hline \multicolumn{8}{|c|}{ Abbreviations: Pearson Corr., Pearson Correlation coefficient } \\
\hline \multicolumn{8}{|l|}{ * P-value < 0.05} \\
\hline
\end{tabular}

Table 5

Distribution of semen quality parameters by sperm donors in the north and south of china. $(\mathrm{N}=667)$

\begin{tabular}{|llll|}
\hline Characteristic & North of China & South of China & $P$ \\
\hline Semen volume, $\mathrm{ml}$ & $\mathrm{N}=521$ & $\mathrm{~N}=146$ & \\
\hline Sperm concentration, $\left(10^{6}\right) / \mathrm{ml}$ & $3.0(2.2-4.0)$ & $3.1(2.4-4.2)$ & 0.189 \\
\hline Progressive motility, \% & $134.0(106.7-170.0)$ & $125.0(99.5-156.3)$ & 0.015 \\
\hline Frozen-thawed sperm concentration, $\left(10^{6}\right) / \mathrm{ml}$ & $71.7(63.0-86.8)$ & $69.7(62.0-79.3)$ & 0.090 \\
\hline Frozen-thawed progressive motility, \% & $53.0(48.0-58.0)$ & $52.0(47.8-58.0)$ & 0.140 \\
\hline Post-thaw survival rate, \% & $0.8(0.8-0.9)$ & $0.8(0.8-0.9)$ & 0.248 \\
\hline Data are shown as median (IQR). ' ${ }^{\prime}$ ' refers to the number of subjects in each category. & \\
\hline
\end{tabular}


Table 6

Distribution of semen parameters by different latitude strata ( $N=1012)$.

\begin{tabular}{|c|c|c|c|c|c|}
\hline \multirow[t]{2}{*}{ Characteristic } & \multicolumn{5}{|c|}{ Latitude (north latitude) } \\
\hline & $\begin{array}{l}45 \text { to } 54 \\
\text { degrees }\end{array}$ & $\begin{array}{l}36 \text { to } 45 \\
\text { degrees }\end{array}$ & $\begin{array}{l}27 \text { to } 36 \\
\text { degrees }\end{array}$ & $\begin{array}{l}18 \text { to } 27 \\
\text { degrees }\end{array}$ & $\mathrm{P}$ \\
\hline & $\mathrm{N}=29$ & $\mathrm{~N}=622$ & $N=310$ & $\mathrm{~N}=51$ & \\
\hline Semen volume, $\mathrm{ml}$ & $2.6(2.2-3.6)$ & $3.0(2.2-4.0)$ & $3.2(2.4-4.2)$ & $3.4(2.4-4.6)$ & 0.084 \\
\hline Sperm concentration, $\left(10^{6}\right) / \mathrm{ml}$ & $\begin{array}{l}146.9(121.5- \\
177.0)^{b}\end{array}$ & $\begin{array}{l}134.0(105.7- \\
170.0)^{b}\end{array}$ & $\begin{array}{l}131.0(104.5- \\
163.2)\end{array}$ & $\begin{array}{l}120.0(95.1 \text { - } \\
158.0)\end{array}$ & 0.040 \\
\hline Progressive motility, \% & $\begin{array}{l}64.0(60.0- \\
73.5)\end{array}$ & $\begin{array}{l}65.0(60.0- \\
70.0)\end{array}$ & $\begin{array}{l}65.0(61.0- \\
71.0)\end{array}$ & $\begin{array}{l}65.0(59.0- \\
71.0)\end{array}$ & 0.758 \\
\hline $\begin{array}{l}\text { Frozen-thawed sperm } \\
\text { concentration, }\left(10^{6}\right) / \mathrm{ml}\end{array}$ & $\begin{array}{l}73.0(61.7- \\
84.8)\end{array}$ & $\begin{array}{l}72.0(63.0- \\
86.1)\end{array}$ & $\begin{array}{l}71.6(62.0- \\
82.0)\end{array}$ & $\begin{array}{l}65.0(60.0- \\
75.3)\end{array}$ & 0.108 \\
\hline $\begin{array}{l}\text { Frozen-thawed progressive } \\
\text { motility, \% }\end{array}$ & $\begin{array}{l}50.0(48.0- \\
56.5)\end{array}$ & $\begin{array}{l}53.0(48.0- \\
58.3)\end{array}$ & $\begin{array}{l}52.0(48.0- \\
58.3)\end{array}$ & $\begin{array}{l}53.0(47.0- \\
58.0)\end{array}$ & 0.464 \\
\hline Post-thaw survival rate, \% & $0.8(0.7-0.9)$ & $0.8(0.8-0.9)$ & $0.8(0.7-0.9)$ & $0.8(0.7-0.9)$ & 0.080 \\
\hline \multicolumn{6}{|c|}{ Data are shown as median (IQR). ' $N$ ' refers to the number of subjects in each category. } \\
\hline
\end{tabular}

Figures 


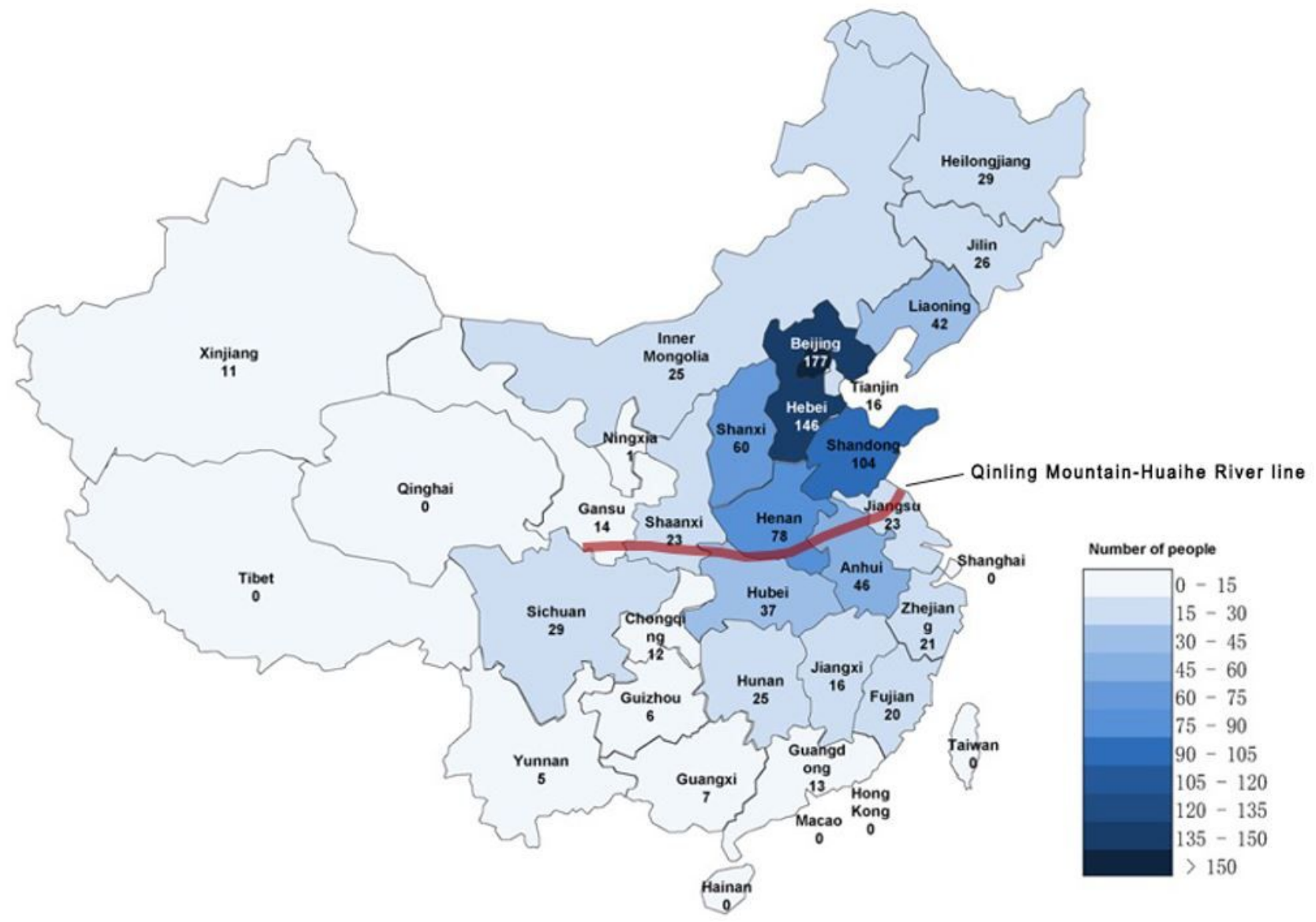

Figure 1

Birthplaces of 1012 donors from 2015 to 2019 in china. The provinces with more than 100 participants were Beijing Municipality (177), Hebei (146) and Shandong (104) provinces. Some of the provinces had a low number of participants included (Less than 15 people), such as the Gansu(14),Chongqing(12),Guizhou(6),Yunnan(5), Guangxi(7), Xinjiang(11) and Guangdong(13) provinces. 

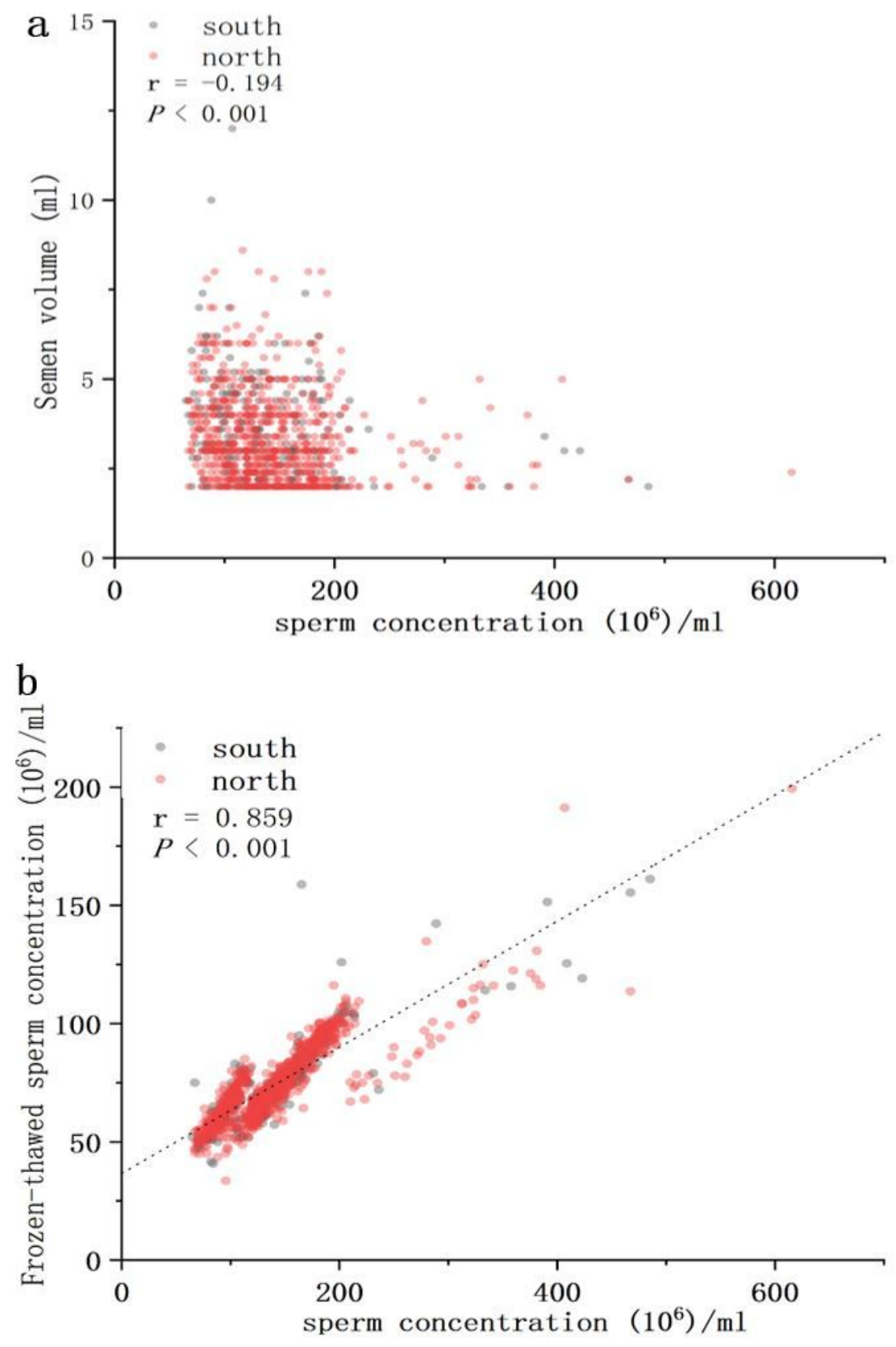

Figure 2

correlation between semen parameters Fig $2 \mathrm{a}$ scatter diagram of sperm concentration and semen volume Fig $2 \mathrm{~b}$ scatter diagram of sperm concentration and frozen-thawed sperm concentration 

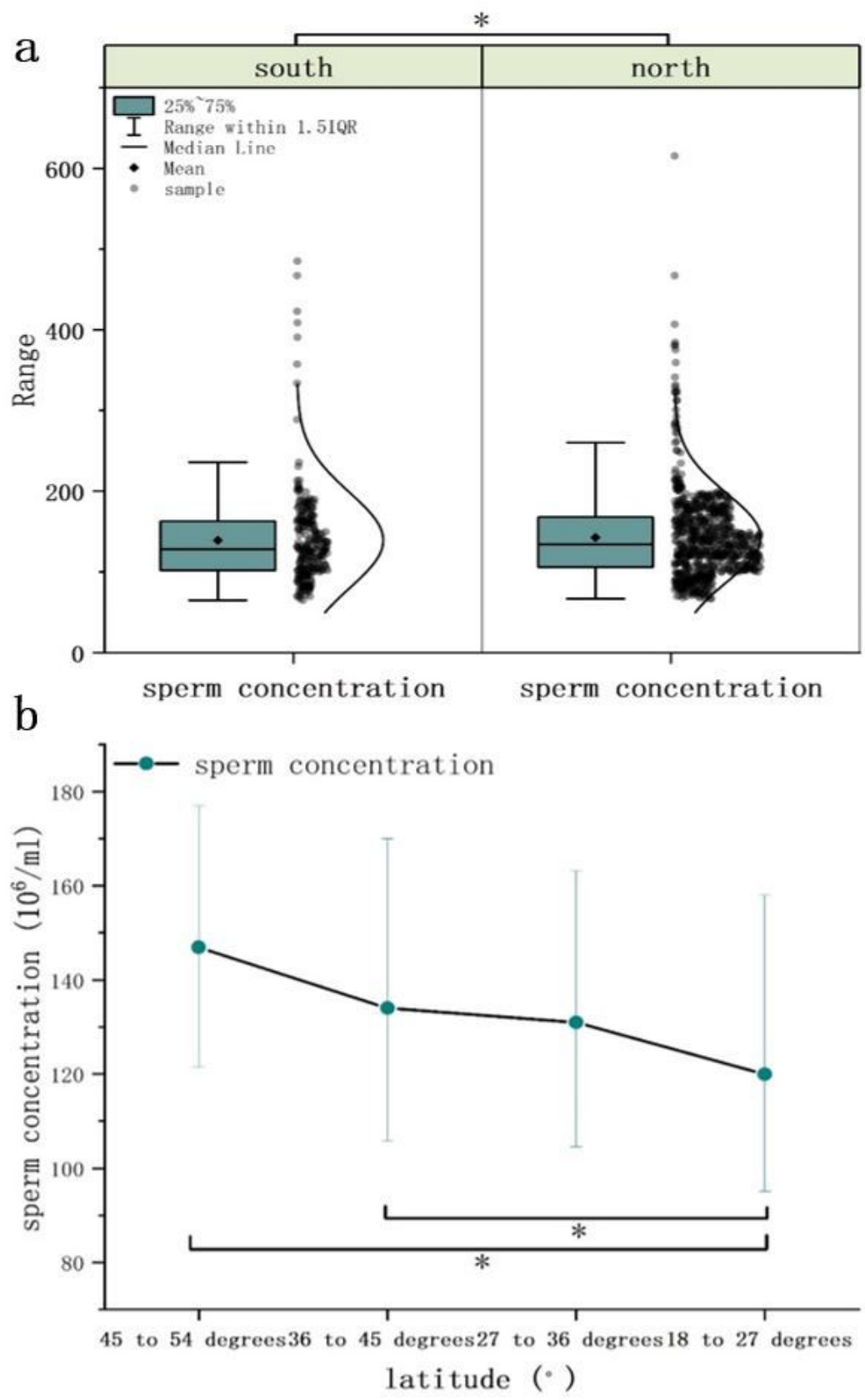

Figure 3

various sperm concentration among different area and latitude Fig 3a box Plot of sperm concentration distribution in refined north and south area. Fig $3 b$ line chart of sperm concentration along with latitude change * $P<0.05$ 